\title{
THREE NEW SEROTYPES OF RHODOCOCCUS EQUI IN PRESCOTT'S SEROTYPING SYSTEM - SHORT COMMUNICATION
}

\author{
László MAKRAI ${ }^{1 *}$, László FODOR ${ }^{1}$, István HAJTÓs ${ }^{2}$, János VARGA ${ }^{1}$ and Béla DÉNES ${ }^{3}$ \\ ${ }^{1}$ Department of Microbiology and Infectious Diseases, Faculty of Veterinary Science, \\ Szent István University, Hungária krt. 23-25, H-1143 Budapest, Hungary; ${ }^{2}$ Government \\ Office for Borsod-Abaúj-Zemplén County, Miskolc, Hungary; ${ }^{3}$ Veterinary Diagnostic \\ Directorate, National Food Chain Safety Office, Budapest, Hungary
}

(Received 13 April 2015; accepted 22 June 2015)

\begin{abstract}
Three new serotypes were found among Rhodococcus equi strains, which could not be assigned into any of the seven serotypes of Prescott's system. Fortythree $R$. equi strains out of 44 previously nontypable ones isolated in Hungary could be allocated into one of the three new serotypes using the agar gel immunodiffusion (AGID) test. The three new suggested serotypes are serotype 8 (proposed reference strain: HNCMB-138003), serotype 9 (proposed reference strain: HNCMB-138004) and serotype 10 (proposed reference strain: HNCMB-138005). Hyperimmune sera produced in rabbits against the new serotypes and reference strains gave precipitation only with their homologous antigens, and no crossreactions were observed. All of the previously nontypable isolates from clinical samples of horses (lung abscesses, intestinal lymph nodes, mediastinal lymph nodes) proved to be serotype 8 , while strains of serotypes 8,9 and 10 could be isolated from nasal and rectal swabs of horses and from the soil. Serotype 9 dominated among the previously nontypable strains of swine origin. One of the previously nontypable human strains was serotype 10 . This serotype was also isolated from pigs, horses and the soil. The description of the three new serotypes can help us reveal new correlations between the host species, geographical origin and serotype of $R$. equi isolates.
\end{abstract}

Key words: Rhodococcus equi, serotyping, AGID

Rhodococcus equi is the causative agent of severe purulent pneumonia of foals (Vázquez-Boland et al., 2013). This bacterium had been first described as Corynebacterium equi nearly one hundred years ago (Magnusson, 1923). As a result of comparative studies the species was later transferred as Rhodococcus equi into the genus Rhodococcus (Goodfellow and Alderson, 1977). Recently, reclassification under the name of Prescotella equi has been suggested (Jones et al., 2013a, 2013b); however, the validity of this questioned (Garrity, 2014).

*Corresponding author; E-mail: makrai.laszlo@aotk.szie.hu; Phone: 0036 (1) 251-9900; Fax: 0036 (1) 251-9260 
From the end of the 1930s, several attempts were made to study the serological features of R. equi strains (Magnusson, 1938; Bruner et al., 1939; Karlson et al., 1940; Bruner and Edwards, 1941; Woodroofe, 1950; Carter and Hylton, 1974), and two serotyping systems (Prescott's and Nakazawa's) were introduced in the laboratory practice.

Prescott's serotyping system (Prescott, 1981) classifies $R$. equi strains into seven serotypes on the basis of capsular polysaccharide antigens using the agar gel immunodiffusion (AGID) test. The exact structure of the polysaccharide capsule of several serotypes was also described (Leitch and Richards, 1990; Severn and Richards, 1990; Finnerty, 1992; Masoud and Richards, 1994). On the other hand, Nakazawa et al. (1983) later assigned $R$. equi strains into 27 serotypes using the slide agglutination test.

The above two serotyping systems were compared by several authors. Prescott's seven type strains were serotyped in Nakazawa's system and Prescott's type strains $1,2,3,4,5,6$ and 7 were classified as serotype 4, 16, 2, 12, 21, 1 and 9, respectively, in Nakazawa's system. The two systems use different serological methods (agglutination and precipitation tests) for the classification and detect different antigens, so they do not correspond with each other (Katsumi et al., 1991; Zimmermann, 1996; Lämmler et al., 1997; Soedarmanto et al., 1998).

Because of its simplicity and specificity, Prescott's serotyping system is much more frequently used for the serotyping of $R$. equi strains. During the last 25 years, a large number of $R$. equi strains were serotyped using Prescott's serotyping system by several authors. In one of our previous studies, $90 R$. equi strains $(23.75 \%)$ out of 379 strains isolated from different sources (swine, soil, horse, human) could not be typed in Prescott's serotyping system (Makrai et al., 2005,2008 ). By re-examining the previously untypable $R$. equi strains using freshly produced hyperimmune sera, 46 of them could be assigned into one of Prescott's serotypes (data not presented).

The aim of the present study was to re-examine strains that repeatedly could not be serotyped, and to describe new capsular serotypes of $R$. equi found among previously untypable strains isolated in Hungary.

\section{Materials and methods}

The 44 untypable strains were isolated from 21 settlements located throughout Hungary. The samples originated from the submandibular lymph nodes of swine (19), from the lungs (3), mediastinal (1) and mesenteric (2) lymph nodes, nasal (4) and rectal swabs (10) of horses, from humans (1) and from the soil (4).

Thirteen $R$. equi strains were selected from our collection of 44 nontypable isolates representing a wide range of sources (different host species, geographical origin, clinical and environmental samples). 
Production of hyperimmune sera in rabbits against the selected 13 untypable strains, preparation of antigen for AGID and the AGID test were carried out as described earlier (Makrai et al., 2008). Each newly produced serum was examined with each of the 13 antigens. Sera that gave identical precipitation bands with these 13 antigens were placed in one group and one serum was used to further examinations. These sera were examined with the accepted seven ( 1 to 7) R. equi type strains (ATCC 33701-33707), too.

\section{Results}

Three distinct new groups were detected among the selected 13 strains that were used for hyperimmune serum production in rabbits. One serum was selected from each of the three groups for further study. Each of the three selected sera gave precipitation with its homologous antigen and did not react with any of the previously known $R$. equi serotypes from 1 to 7 . Based on these results, three new serotype candidates of $R$. equi (serotypes 8,9 and 10) are proposed. The three suggested type strains have been deposited at the Hungarian National Collection of Medical Bacteria as $R$. equi strains HNCMB-138003 (serotype 8), HNCMB-138004 (serotype 9) and HNCMB-138005 (serotype 10). All but one untypable strain (43 strains) gave precipitation bands with one of the three sera; they could be assigned into one of the suggested new serotypes.

Serotype 9 dominated among the previously nontypable 44 strains $(47.73 \%)$, but serotypes 8 and 10 also represented a significant proportion (serotype 8 : $36.36 \%$, serotype 10: $13.64 \%$ ), while one strain (2.27\%) could not be typed.

Most of the strains isolated from horses belonged to serotype 8, while strains from the submandibular lymph nodes of pigs were mainly of serotype 9. The previously nontypable human isolate belonged to serotype 10 . The distribution of previously nontypable $R$. equi strains according to origin and serotype is shown in Table 1.

\section{Discussion}

Two systems are used for serotyping of $R$. equi strains: Prescott's (1981) and Nakazawa's (Nakazawa et al., 1983) systems. These two systems are not compatible, since they detect different antigens in different serological tests (agar gel precipitation and slide agglutination test, respectively). Certain type strains of both systems can be assigned into one of the serotypes of the other one, but there is no correlation between them (Zimmermann, 1996; Lämmler et al., 1997).

When using either of the two systems, some strains prove to be untypable (Mutimer et al., 1982; Zimmerman, 1996; Lämmler et al., 1997). Ninety-eight $R$. equi strains of different origin were serotyped in both serotyping systems by 
Lämmler et al. (1997). When using Prescott's system, his strains could be assigned into five serotypes and 12 strains were not typable, while in Nakazawa's system they could be assigned into 11 serotypes and only three strains were not typable. Although much fewer nontypable strains were detected in Nakazawa's system than in Prescott's system, the latter system has become much more widely used since it is easy to carry out, the reactions are clear and there are no cross-reactions. With the addition of the three new serotypes the efficacy of Prescott's system has increased considerably.

Table 1

Assignment of previously nontypable Rhodococcus equi strains into three new serotypes according to their origin

\begin{tabular}{|c|c|c|c|c|c|c|}
\hline & \multirow{2}{*}{ Origin } & \multicolumn{3}{|c|}{ New serotypes } & \multirow{2}{*}{$\begin{array}{l}\text { Non- } \\
\text { typable }\end{array}$} & \multirow{2}{*}{ Total } \\
\hline & & 8 & 9 & 10 & & \\
\hline \multirow[t]{5}{*}{ Horse } & lung abscesses & 3 & - & - & - & $\begin{array}{c}3 \\
(6.82 \%)\end{array}$ \\
\hline & intestinal lymph nodes & 2 & - & - & - & $\begin{array}{c}2 \\
(4.55 \%)\end{array}$ \\
\hline & mediastinal lymph nodes & 1 & - & - & - & $\begin{array}{c}1 \\
(2.26 \%)\end{array}$ \\
\hline & nasal swabs & 3 & - & 1 & - & $\begin{array}{c}4 \\
(9.1 \%)\end{array}$ \\
\hline & rectal swabs & 5 & 3 & 2 & - & $\begin{array}{c}10 \\
(22.73 \%)\end{array}$ \\
\hline Soil & from horse environment & 1 & 1 & 1 & 1 & $\begin{array}{c}4 \\
(9.1 \%)\end{array}$ \\
\hline Swine & submandibular lymph nodes & 1 & 17 & 1 & - & $\begin{array}{c}19 \\
(43.18 \%)\end{array}$ \\
\hline Human & & - & - & 1 & - & $\begin{array}{c}1 \\
(2.26 \%)\end{array}$ \\
\hline Total & & $\begin{array}{c}16 \\
(36.36 \%)\end{array}$ & $\begin{array}{c}21 \\
(47.73 \%)\end{array}$ & $\begin{array}{c}6 \\
(13.64 \%)\end{array}$ & $\begin{array}{c}1 \\
(2.27 \%)\end{array}$ & $\begin{array}{c}44 \\
(100 \%)\end{array}$ \\
\hline
\end{tabular}

Among the previously not typable $44 R$. equi strains three new serotypes were found. They are proposed to represent serotypes 8, 9 and 10 of $R$. equi, respectively. They proved to be independent, the proposed type strains of these new suggested serotypes reacted only with their homologous sera and these sera did not show cross-reactions with the seven accepted type strains of $R$. equi. The suggested reference strains for these serotypes are $R$. equi strain HNCMB138003 (serotype 8), HNCMB-138004 (serotype 9) and HNCMB-138003 (serotype 10). Forty-three out of 44 formerly untypable $R$. equi could be serotyped using the three new type sera of these three suggested new serotypes. 
The newly serotyped strains isolated from clinical samples of different species showed a characteristic serotyping pattern, while strains isolated from nasal and rectal swabs and soil samples showed a significant diversity, like in the case of other serotypes. Virulence markers (vapA, vapB plasmid profile) of the strains of the three new serotypes are to be examined in the future, as has been performed with the serotypes described previously (Makrai et al., 2005).

Among the previously nontypable strains isolated from horses serotype 8 , while among those isolated from swine serotype 9 was the dominant serotype, and the previously nontypable human isolate belonged to serotype 10 .

The classification of previously nontypable $R$. equi strains into the three new serotypes can reveal new relationships between the host species, geographical origin and serotype of $R$. equi isolates.

\section{Acknowledgements}

This study was supported by the Hungarian Scientific Research Fund grant OTKA F26597. Our thanks are due to Prof. J. F. Prescott (Department of Pathobiology, Ontario Veterinary College, University of Guelph, Guelph, Canada) and Prof. Ch. Lämmler (Justus-Liebig-Universität, Gießen, Germany), who provided the type strains of $R$. equi (ATCC 33701-33707).

\section{References}

Bruner, D. W. and Edwards, P. R. (1941): Classification of Corynebacterium equi. Kentucky Agric. Exp. Stn. Bull. 414, 92-107.

Bruner, D. W., Dimock, W. W. and Edwards, P. R. (1939): The serological classification of Corynebacterium equi. J. Infect. Dis. 65, 92-96.

Carter, G. R. and Hylton, G. A. (1974): An indirect hemagglutination test for antibodies to Corynebacterium equi. Am. J. Vet. Res. 35, 1393-1395.

Finnerty, W. R. (1992): The biology and genetics of the genus Rhodococcus. Ann. Rev. Microbiol. 46, 193-218.

Garrity, G. M. (2014): Conservation of Rhodococcus equi (Magnusson 1923) Goodfellow and Alderson 1977 and rejection of Corynebacterium hoagii (Morse 1912) Eberson 1918. Int. J. Syst. Evolut. Microbiol. 64, 311-312.

Goodfellow, M. and Alderson, G. (1977): The actinomyces genus Rhodococcus: a home for the 'rhodochrous' complex. J. Gen. Microbiol. 100, 99-122.

Jones, A. L., Sutcliffe, I. C. and Goodfellow, M. (2013a): Prescottia equi gen. nov.: a new home for an old pathogen. Antonie van Leeuwenhoek 103, 655-671.

Jones, A. L., Sutcliffe, I. C. and Goodfellow, M. (2013b): Proposal to replace the illegitimate name Prescottia equi Jones et al. 2013 with the genus name Prescotella gen. nov. and to replace the illegitimate combination Prescottia equi Jones et al. 2013 with Prescotella equi comb nov. Antonie van Leeuwenhoek 103, 1405-1407.

Karlson, A. G., Moses, H. E. and Feldman, W. H. (1940): Corynebacterium equi (Magnusson, 1923 ) in the submaxillary lymph nodes of swine. J. Infect. Dis. 67, 243-251. 
Katsumi, M., Kodama, N., Miki, Y., Hiramune, T., Kikuchi, N., Yanagawa, R. and Nakazawa, M. (1991): Typing of Rhodococcus equi isolated from submaxillary lymph nodes of pigs in Japan. J. Vet. Med. B 38, 299-302.

Lämmler, C., Zimmermann, B. and Fuhrmann, C. (1997): Serological properties of Rhodococcus equi isolates of various origins determined with two typing systems. Med. Sci. Res. 25, $187-189$.

Leitch, R. A. and Richards, J. C. (1990): Structural analysis of the specific capsular polysaccharide of Rhodococcus equi serotype 1. Biochem. Cell. Biol. 68, 778-789.

Magnusson, H. (1923): Specific infectious pneumonia in foals. A new pyogen in horse [in German]. Arch. Wiss. Prakt. Tierheilk. 50, 22-38.

Magnusson, H. (1938): Pyaemia in foals caused by Corynebacterium equi. Vet. Rec. 50, 1359-1468.

Makrai, L., Dénes, B., Hajtós, I., Fodor, L. and Varga, J. (2008): Serotypes of Rhodococcus equi isolated from horses, immunocompromised human patients and soil in Hungary. Acta Vet. Hung. 56, 271-279.

Makrai, L., Takayama, S., Dénes, B., Hajtós, I., Sasaki, Y., Kakuda, T., Tsubaki, S., Major, A., Fodor, L., Varga, J. and Takai, S. (2005): Characterization of virulence plasmids and serotyping of Rhodococcus equi isolates from submaxillary lymph nodes of pigs in Hungary. J. Clin. Microbiol. 43, 1246-1250.

Masoud, H. and Richards, J. C. (1994): Structural elucidation of the specific capsular polysaccharide of Rhodococcus equi serotype 7. Carbohydr. Res. 252, 223-233.

Mutimer, M. D., Prescott, J. F. and Woolcock, J. B. (1982): Capsular serotypes of Rhodococcus equi. Aust. Vet. J. 58, 67-69.

Nakazawa, M., Kubo, M., Sugimoto, C. and Isayama, Y. (1983): Serogrouping of Rhodococcus equi. Microbiol. Immunol. 27, 837-846.

Prescott, J. F. (1981): Capsular serotypes of Corynebacterium equi. Can. J. Comp. Med. 45, 130-134.

Severn, W. B. and Richards, J. C. (1990): Structural analysis of the specific capsular polysaccharide of Rhodococcus equi serotype 2. Carbohydr. Res. 206, 311-332.

Soedarmanto, I., Zhicai, W., Setyamahanani, A. and Lämmler, C. (1998): Pheno- and genotyping of Rhodococcus equi isolated from faeces of healthy horses and cattle. Res. Vet. Sci. 64, 181-185.

Vázquez-Boland, J. A., Giguere, S., Hapeshi, A., MacArthur, I., Anastasi, E. and Valero-Rello, A. (2013): Rhodococcus equi: The many facets of a pathogenic actinomycete. Vet. Microbiol. 167, 9-33.

Woodroofe, G. M. (1950): Studies on strains of Corynebacterium equi isolated from pigs. Aust. J. Exp. Biol. Med. Sci. 28, 399-409.

Zimmermann, B. (1996): Isolation and characterisation of Rhodococcus equi from test probes of different animal species [in German]. Inaugural-Dissertation, Justus Liebig Universität, Gießen. 